\title{
FIRING THE UNPRODUCTIVE EMPLOYEE: WILL CIVIL SERVICE REFORM MAKE A DIFFERENCE?
}

\author{
Carolyn Ban \\ U. S. Office of Personnel Management \\ Edie N, Goldenberg \\ The University of Michigan \\ Toni Marzotto \\ Towson State University
}

\begin{abstract}
Civil service reform included a set of changes intended to facilitate the firing of consistently unproductive employees. This article describes the background and logic of these changes, reviews the status of their implementation, and offers preliminary evidence on their consequences for personnel management in the federal government.
\end{abstract}

\section{Introduction}

The Civil Service Reform Act of 1978 (CSRA) and associated reorganizations constitute the most significant effort to restructure the federal personnel management system since the Pendleton Act a century earlier. The purpose of the reform is to increase the authority of managers in a number of personnel areas, while at the same time protecting employees against arbitrary personnel actions.

This paper focuses on one key set of reform mechanisms, those changes intended to facilitate the release of consistently unproductive employees. The background and logic of the reforms are described and an update provided concerning the status of implementation and results thus far. Although four years have elapsed since the passage of the Act, we have limited experience with many central reform provisions which have only recently been fully implemented. Nevertheless, the general dimensions of reform consequences are becoming clear.

\footnotetext{
* The authors wish to thank the following people for their assistance: Wilma Lehman, Tom Johnson, and Charles Gossett. The views expressed are those of the authors and not the official position of the Office of Personnel Management. An earlier version of this paper was presented at the Annual meeting of the Mid-West Political Science Association, Chicago, 1980.
} 


\section{Reform Background, Logic and Changes}

The Nature of the Problem:

The Analysis of the Presidenc's Personnel Management Project

The authors of the President's Personnel Management Project (1977), which provided the basis for much of the Civil Service Reform Act, identified a number of problems with the federal personnel system. One area they saw as having problems was the firing of unproductive employees. On the one hand, they recognized a number of factors which deterred managers from taking actions against poor performers. On the other hand, they were concerned about the possibility of arbitrary or political abuse in such actions. Correcting these problems simultaneously is difficult because of the inherent tension among them.' For example, expanding managers' authority provides more opportunity for abuses. Conversely, guaranteeing due process can lead to excessive delays and rigidity. Nevertheless, civil service reform includes a variety of provisions designed to address these problems.

\section{Factors deterring managers from taking actions against poor performers}

While supervisors always had the authority to remove or demote poor performers, they avoided doing so for a number of reasons identified by the Personnel Management Project (PMP) report (1977: 40). The first problem area was procedural. The PMP saw a lack of adequate procedures for identifying poor performance, and for taking appropriate action once poor performance had been identified. The second problem area was the complexity and protracted nature of appeals procedures, which inhibited managers from taking actions. The third problem was the attitudes and behaviors of supervisors and managers themselves. Some supervisors failed to counsel employees at an early stage or to explain how they could improve their performance. Other supervisors greatly over-extended their efforts to counsel or reassign employees, but were unwilling to fire employees whose performance did not improve.

\section{Arbitrary or political abuse}

The authors of the PMP (1977: 52) recognized that providing greater flexibility to managers in this, as in other areas, brought with it the potential for abuse. At the same time, they noted that "the complexity and red tape which now surround personnel management processes may serve as a refuge for the incompetent and yet do little to prevent abuses motivated by politics, cronyism, or special interests. What is needed is a reorganization which will reduce the red tape on one hand and which will provide strong and effective merit protection on the other." The PMP also expressed concern about past abuses, some of which were politically motivated, and stated that "The Civil Service Commission has not been able to provided adequate protection against these abuses." 


\section{The Nature of the Reforms}

The reforms contained in the Act designed to address these problems focused upon four concerns.

1. Procedures for appraising performance and for taking actions based on poor performance

Civil service reform requires every agency to develop new procedures for appraising their employees' performance. These sytems are based on the employees' actual activities, rather than on traits or personal characteristics. While each agency may develop an appraisal system to meet its needs, each system breaks an individual's appraisal down into specific job elements and standards against which performance is rated. These elements and standards are developed by the supervisor, ideally with the employee's participation.

Prior to reform, one set of procedures for downgrading or removing a federal employee applied, regardless of the reasons for the action. This set of procedures was termed "adverse actions." " The reform created new procedures, "actions based on unacceptable performance," linked to the new performance appraisal systems. The intent was to make it easier to dismiss employees for poor performance than it had been previously. Each performance appraisal system requires supervisors to designate some performance elements and standards as "critical." Under the new procedures, employees can be dismissed or demoted if their performance on one or more critical elements is unacceptable. This is a significant change, since managers no longer must consider employees' performance as a whole; rather, individuals can be fired or demoted if they fail to perform acceptably on any single critical element. Civil service reform also requires a lesser standard of proof for actions based on unacceptable performance. $^{3}$

\section{Improving the appeals process}

Reform in the area of appeals focused both on streamlining the process, and on enhancing the legitimacy of the employee appeals process. The authors of the PMP report (1977: 40) saw the "incredible length" of the appeal process and its extreme complexity as "one of the greatest deterrents in Government to discharging employees whose performance is unsatisfactory." The Reform Act attempted to address this problem in several ways, first by reducing the number of levels of appeal available, ${ }^{4}$ and second, by requiring the Merit Systems Protection Board, which was established to hear appeals, to set a time limit within which appeals must be processed.

The Act also made a number of changes to enhance the legitimacy of the appeals process. First, it separated the function of hearing appeals from the function of issuing personnel rules and regulations. Prior to reform, adverse action appeals were heard by the Federal Employee Appeals Authority, a part of the Civil Service Commission. Civil service reform created an independent 
body (MSPB) to hear appeals. With this separation of functions, OPM is expected to speak clearly as the representative of management, while MSPB serves as an impartial arbiter, taking a neutral rather than pro-management stance.

From the manager's point of view, not only was the appeals process long and complex, but actions were frequently overturned because of trivial procedural errors by management. One example, taken from a General Accounting Office report, conveys the dimensions of the problem:

An agency fired an employee for beating his supervisor with a baseball bat. FEAA (The Federal Employee Appeals Authority) overturned his removal, contending the agency had not given the employee adequate notice of firing. The agency had to reinstate the employee in the same position, under the same supervisor, and reimburse the employee eight month's back pay (GAO, 1978).

The Reform Act changed the law in order to reduce reversals on appeal for minor procedural errors. Now, a procedural error invalidates an action only if it actually is "harmful." This applies both to adverse actions and actions based on unacceptable performance. MSPB defines harmful error as "error by the agency in the application of its procedures which, in the absence of cure of the error, might have caused the agency to reach a conclusion different than the one reached." "Unless the procedural error is harmful, MSPB cannot use it as a basis for reversal.

\section{Changing the attitudes of supervisors and employees}

If new procedures are going to have any effect, then the attitudes of supervisors and employees will also have to change. Supervisors must be willing both to counsel employees with problems and to fire or demote those who do not improve. Employees must also have confidence in the system, i.e., they must expect that poor performers will not be tolerated, and that the system will be equitable.

Changes in attitudes are harder to legislate than new procedures. The legislation, and OPM's implementing regulations, leave to agencies a great deal of discretion in the development of their performance appraisal systems, and also leave to agencies the responsibility for training supervisors in their use.

\section{Preventing political abuse}

While the Act permitted supervisors to fire or demote employees whose work was clearly poor, the intent of the Act was also to protect employees from arbitrary or politically motivated punishment. The excesses of the Nixon administration were fresh in peoples' minds, but the sources of concern and legal precedents regarding federal employee job protections predate Nixon. Over the past several decades the courts have become increasingly involved in the administrative details of personnel management.

Prior to the 1950s, the law on dismissing government employees was fairly simple: as far as the Constitution was concerned, government employees worked 
at the pleasure of their superiors. This principle, usually referred to as the "doctrine of privilege," was neatly summed up in an oft-quoted statement by Justice Holmes: "the petitioner [a policeman] may have a constitutional right to talk politics, but he has no constitutional right to be a policeman" (McAuliffe v. New Bedford, 1892: 216,220). The doctrine was based on the premise that an individual has no constitutional right to public employment and consequently can be fired (or not hired) for a wide range of reasons.

More recently, "due process" provisions have been repeatedly invoked and expanded in cases dealing with public employment. A doctrine of substantial interest has replaced the doctrine of privilege. The courts have held that the conditions imposed by the government upon civil servants which interfere with their ordinary constitutional rights as citizens cannot be justified simply on the basis that there is no constitutional right to public employment. Consequently, removing an individual from public employment may violate the constitutional requirement of procedural due process (see Rosenbloom, 1977). The Act includes provisions designed to protect employees from political abuse. A set of merit system principles was written into law, as well as a number of detailed formal statutory protections.

Title I of the Act establishes in law both the basic merit principles and the specific personnel practices that are prohibited in the federal personnel system. The President and agency heads are responsible for assuring that personnel management in the Executive Branch is carried out in accordance with these principles. Specifically, Title I states that not only agency heads, but also those to whom agency heads delegate personnel management authority, are responsible for preventing prohibited personnel practices and for properly executing all civil service laws and regulations.

Managers are expected to protect their career employees against improper political influence and personal favoritism by recruiting, hiring, advancing and retaining them on the basis of individual ability and performance without regard to political affiliation, race, color, national origin, sex, marital status, age or handicapping condition. Employees who do not perform adequately, and who cannot or will not improve, are expected to be fired. These tenets are among those commonly referred to as the "merit principles."

While these principles are implicit in earlier laws, executive orders, rules and regulations, no comprehensive statement of the merit principles that apply to federal personnel management existed prior to civil service reform. Of course, codification of merit system principles will not by itself prevent abuse, but their presence in the Act underlines their importance and reminds managers to remain sensitive to merit principles as the other reform provisions are implemented.

The Act also provides formal statutory protections for all employees subject to dismissals or downgradings. These include formal 30 days advance written notice, reasonable time to answer orally and in writing, the right to representa- 
tion by an attorney or other representative, and a written decision with specific reasons for the action. In addition, the individual has a right to appeal to the MSPB or to grieve through union grievance procedures. ${ }^{6}$ These protections were previously provided by staitute only to veterans ' although they had been extended to others by executive order in 1974.

\section{The Status of Implementation and Results to Date}

Although it may be too early to pass final judgment on these provisions of the Act, it is not too early to make some preliminary assessments. This section describes the process of implementation, including the problems encountered and the results to date.

\section{Implementing New $\mathbb{P r o c e d u r e s}$ for Performance Appraisal and for Taking Actions on Unacceptable Performance}

While implementation of some sections of the Act began in January, 1979 the authors of the Act recognized that developing new performance appraisal systems and putting them into place would take some time. As a result the deadline for implementation of this provision was October, 1981 and relatively few agencies had systems in place before that date. OPM issued interim regulations to allow agencies to begin using the new provision for taking actions based on unacceptable performance. However, the newly created MSPB, which was empowered to review all OPM regulations, ruled in the case of Wells $v$. Harris (1979) that OPM's interim regulations were invalid and that agencies could take performance-based actions under the new procedures only after they had established their performance appraisal systems.

In gauging the impact of this ruling, it is necessary to keep in mind two points. First, MSPB ruled that agencies could continue to take performance-based actions under the pre-reform procedures until their performance appraisal systems were in place. While the evidentiary requirements under these procedures are somewhat more stringent, agency personnel specialists were already familiar with them and were able to continue to take actions in clear-cut cases. Second, what was required by MSPB for an agency's performance appraisal system to be considered established was quite lenient. Essentially, if OPM approved the system, it could be considered established. Shortly after the Wells decision, OPM stepped up its approval process.

Given that MSPB decided in the Wells case that agencies could not use the new procedures for taking performance-based actions until their new performance appraisal systems were in place, few agencies have yet used them. Agencies were required to have their new performance appraisal systems in place by October 1, 1981, and virtually all agencies met their deadline, but, as of early 1982, few agencies have had systems in place long enough so that appraisals have been conducted and actions based on those appraisals have been taken. 


\section{Effects of the New Appeals Procedures}

One goal of the Act was to expedite the appeals process. In this area results are mixed. When the legislation was being designed, the Administration hoped for a 60-day turnaround from MSPB. However, the legislation only required MSPB to set a time limit and did not specify what it should be. In fact, MSPB has set a limit of 120 days for field office cases and that limit is usually met. ${ }^{8}$ It has imposed no such limit on cases appealed to the full Board, and delays of several months are not unusual there.

Another goal of the Act was to reduce the number of cases overturned for minor technical errors. At first glance, it would appear that this goal has been met. Based on a sample of approximately 1,000 cases tracked by OPM, only four percent of cases adjudicated were reversed for harmful procedural error. This compares favorably with a 15 percent rate of reversal for procedural error in both 1978 and 1977. On the other hand, MSPB has been reversing a much larger number of cases on their merits than did the Federal Employee Appeals Authority. Based on the sample of 1,000 cases, almost 20 percent were overturned based on their merits, compared to only 10 percent in 1977 and 1978.

There are two reasons for this change. First, under the previous appeals system, cases were reversed on procedures before their merits were even considered. Now more cases survive to face the test of merit. Second, MSPB has introduced new criteria for establishing merit. One area where important new precedents have been set is the link between an employee's off-duty misconduct and his or her job and official responsibilities. MSPB has been requiring a much more direct relation between the two in order to uphold an action based on off-duty misconduct than had been the case in the past. In the major decision in this area, Merritt v. Justice (1981), the Board found that the off-duty use of drugs by a law enforcement official, who had shared them with work associates, was not egregious misconduct and that it was the agency's burden to prove the nexus or link. The Board did not believe that the agency had done so, and reversed the initial decision.

Another area in which there has been a significant change from previous practice is in determining the appropriateness of penalties. Under the previous system, agency actions were either upheld or overturned in toto. MSPB regards their charge as including the right to review not just merits of the action but also the appropriateness of the penalty levied by the agency and to change inappropriate penalties if the discipline imposed by the agency is arbitrary, capricious, or unreasonable (Douglas v. VA, 1981).

Thus, while the number of actions reversed for procedural errors has decreased, as the authors of the Act had planned, the sharp increase in the number of reversals for merit means that the total number of cases reversed has gone down only one percent (from 25 percent to 24 percent). This is an unanticipated 
consequence of the creation of a new agency to hear appeals, and one which may have far-reaching effects.

\section{Supervisor and Employee Attiudes}

Perhaps the most important intended effect of these reforms is to make employees believe that job performance matters. For changes in disciplinary rules to be effective, supervisors must believe both that their agency's performance appraisal system is useful for evaluating employee performance and that the procedures for taking an action based on unacceptable performance are workable, i.e., not too complex or time-consuming. Moreover, eventually employee attitudes must change as well; they must believe that action will be taken against consistently poor performers.

OPM administers surveys periodically in order to see to what extent these attitudes are changing. The baseline survey, conducted in May 1979 (U. S. Office of Personnel Management, 1980) showed, room for improvement. Many employees failed to perceive a strong connection between poor performance and the likelihood of negative sanctions. As Graph 1 shows, only approximately one-third of the workforce felt that they would be demoted or removed from their job if they performed poorly. Supervisory personnel perceived negative consequences as slightly more likely. However, even at these levels, generally less than 50 percent saw a relationship between poor performance and negative consequences. About 30 percent of federal employees felt that their organizations moved marginal and unsatisfactory workers to positions where they could be ignored and that disciplinary actions were avoided because of the paperwork required.

Attitudes toward the performance appraisal system in place before reform were quite negative. Approximately one-half ( 49 percent) of surveyed employees felt that their performance rating presented a fair and accurate picture of their actual job performance. Over one-half ( 55 percent) agreed that there was a tendency for supervisors to give the same performance rating regardless of how well people perform their jobs. Further, as Graph 2 shows, many employees, particularly those in non-supervisory positions, questioned the fairness of disciplinary actions taken.

OPM's second survey, conducted in late 1980 (U. S. Office of Personnel Management, forthcoming), covered only senior-level federal employees (GS 13-15 and SES members). Since it is supervisors who must initiate actions, their willingness to do so and their perceptions of the fairness of the process are critical. In reviewing the results, we find no significant changes in attitudes among supervisors so far. For example, less than 50 percent of supervisors in both 1979 and 1980 agreed that "When an employee continues to do his/her job poorly supervisors here will take the appropriate corrective action" (44 percent agreed in $1979 ; 47$ percent in 1980). Slightly more supervisors in 1980 than 


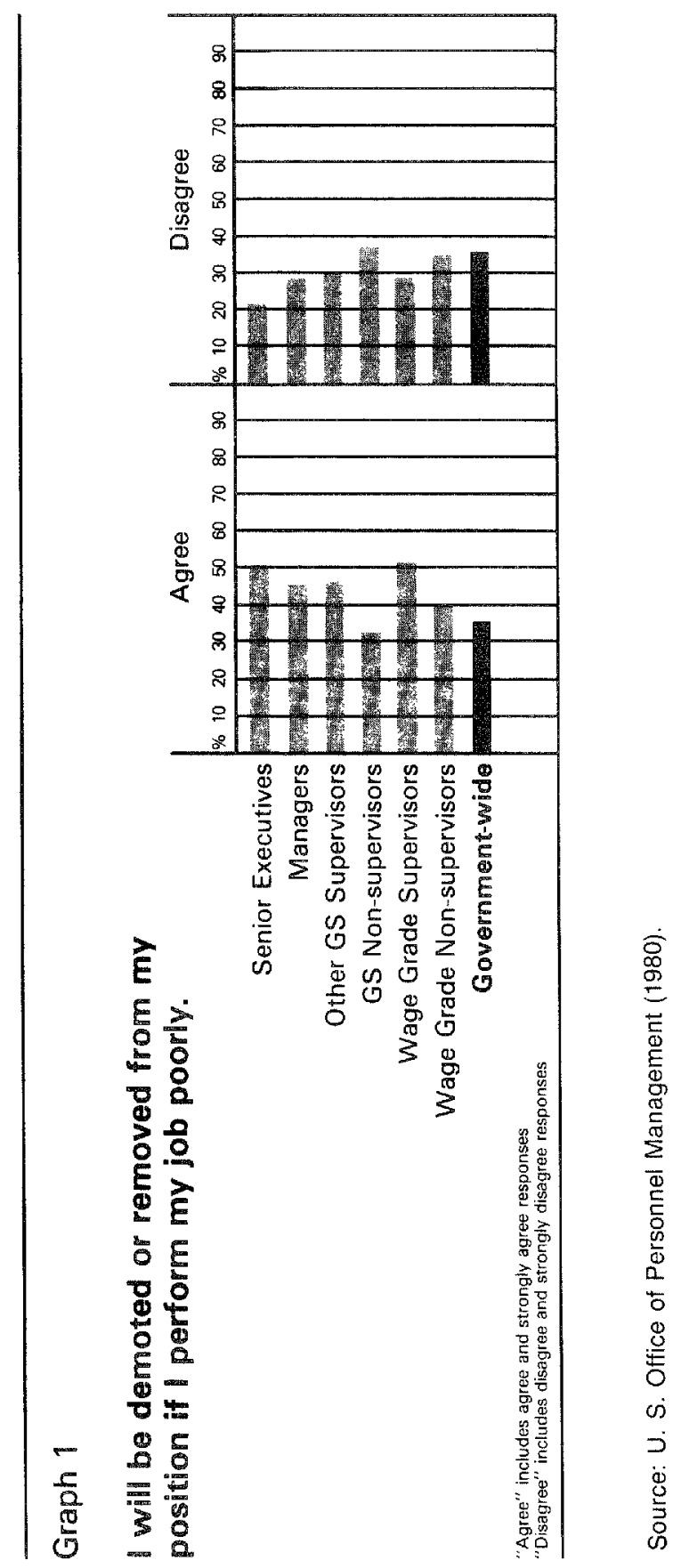




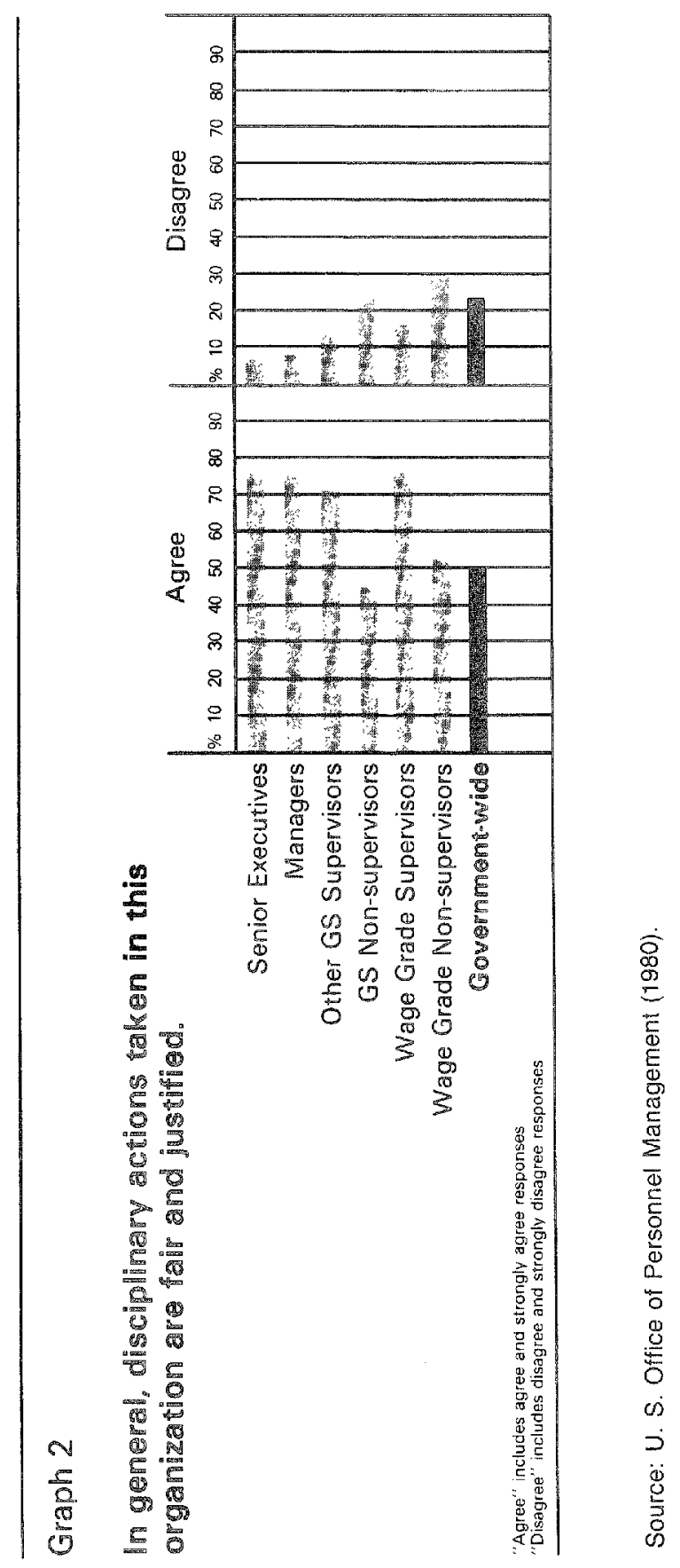


in 1979 felt that "Downgrading or removing poor performers in this organization is avoided because of the paperwork that is required" (43 percent agreed in $1979 ; 51$ percent in 1980 ).

Furthermore, there appears to be both a general lack of information about the reforms among supervisors, and a skepticism about their effects. When asked to compare CSRA procedures for taking action against poor performers to preCSRA procedures, over three-quarters of supervisors said either that they did not know what changes had taken place or that they had not noticed any change. Forty-five percent of supervisors said they did not know if the CSRA procedures were more rapid, and 36 percent said that the new procedures took the same amount of time to process as the pre-CSRA procedures. Forty-one percent of supervisors said that they did not know if the current procedures were more or less complex than pre-CSRA procedures, and 37 percent reported that the old and new procedures were equally complicated.

\section{Political Abuse}

As these new procedures have gone into effect, has there been an increase in arbitrary actions or in dismissals for political reasons? A superficial reading of the statistics showing an increase in cases reversed on their merits might lead one to conclude that there has been. In fact, in very few of these cases did the defendant claim that the firing was for arbitrary or political reasons. Even during a highly-charged transition period, there have been few public charges of political abuses in firings or reassignments. And a recent study of career federal executives during the transition found no involuntary reassignments prior to the 120-day time limit set by law. ${ }^{9}$

\section{Conclusions}

One problem in evaluating the effects of these provisions is that they were initially oversold. In advocating the Act, Carter emphasized the fact that few federal employees were terminated for poor performance, thus stressing the negative aspects of the Act. The implication conveyed was that there were thousands of incompetents on government payrolls and that, as soon as their hands were untied, federal managers would rush to dismiss them. In fact, of course, the situation in most agencies is more complex. Managers are much less likely to be faced with employees who are rank incompetents than with marginal employees who do not perform up to their full potential, and who require counseling or reassignment.

In addition to reinforcing the negative image of the bureaucracy, the overselling of the Act set up the number of people fired as the de facto criterion for the success of these provisions. The issue should not be simply whether more people are fired but whether supervisors and managers deal appropriately with 
problem employees. But looking at the number of people fired is much simpler than examining the dynamics of the supervisor-subordinate relationship.

Furthermore, President Carter used a statistic of questionable validity, giving the impression that only 226 people had been fired in 1977 , when in fact the total number was in the thousands. Nonetheless, if we look only at the simple criterion of the number of people fired, the early results are not encouraging. A comparison of the number of actions taken in 1978 and 1980 shows a considerable decrease, from 7,709 in 1978 to 6,781 in $1980 .^{10}$

But, as should be clear, there are a number of possible explanations for this decline. The Wells decision and confusion about the new procedures may have had a temporary chilling effect on agencies' willingness to take actions. A more likely reason lies in the fact that a hiring freeze was in place for most of 1980. During a freeze, supervisors have no incentive to fire any but the most egregiously poor performers, since they will not be able to hire replacements for people they discharge.

But it is also possible that these provisions of the Act will end up having very little effect. The reforms were largely mechanistic, focusing on new formal procedures for taking actions and for appeals. The authors of the Personnel Management Project recognized that a large proportion of the problem rested with supervisors and managers themselves. Simply creating new procedures without communicating these changes aggressively or training supervisors in their use cannot be expected to cause major change. In fact, many supervisors receive little if any training in such matters as conducting performance appraisals and dealing with problem employees. And, in the current era of severe budget cuts, training is one of the first things to be dropped. Evidence to date is that most managers do not know about the reforms in this area, and that those who do are skeptical about their effects. Without increased efforts to communicate these changes, and to train supervisors in how to use the new procedures, we cannot be overly optimistic about their long-range effects (on these points, see Bellone above and Flanders and Klauss below - Ed.).

\section{NOTES}

\footnotetext{
'Alan K. Campbell, former Director of the U. S. Office of Personnel Management, has even suggested that the changes produced by CSRA are in some ways "almost contradictory" in nature. See Campbell (1977).

"Technically speaking, an "action" is any change in personnel status. In this discussion, we are concerned with three types of actions: dismissals, demotions, and suspensions, An adverse action procedure can be taken against any employce "for such causc as will promote the efficiency of the service." The majority of these actions are for misconduct, which can range all the way from raking leave without permission to assault and battery or murder. CSRA also created a new category of short suspensions. Only suspensions for more than 14 days are now considered full adverse actions. Short suspensions, those less than 14 days, are not appealable.
} 
"Prior to reform, all adverse actions had to be based on a "preponderance of the evidence." Now that standard is reduced to "substantial evidence" for performance-based cases. This change was expected to make il easier for supervisors and managers to develop the documentation necessary to take such actions and to support their actions on appeals. MSPB recently stated the distinction between the two as follows: "Unlike the preponderance standard, which requires evidence that a reasonable person would accept as sufficient to find a contested fact more probably true than untrue, the substantial evidence standard requires evidence of such quality and weight that reasonable and fair-minded persons in exercising impartial judgment might reach different conclusions. See Parker v. Defense Logistics Agency (1980).

${ }^{4}$ Appeals may now proceed through the following steps: 1 ) initial appeal to Merit Systems Protection Board (MSPB) field offices; 2) request to the full Board to reopen the case; and 3) appeal to the U. S. Court of Appeals or Court of Claims. Decisions of negotiated grievances may also be appealed in court.

MSPB regulation appearing at 5 CFR. 1201.56 (c) (3). MSPB recently clarified the definition of "harmful crror." ". . . the question is whether it was within the range of appreciable probability that the error had a harmful effect upon the outcome before the ageney . . . the decisive factors are the closeness of the agency's decision, the centrality of the issue affected by the error, and any steps taken to mitigate the effect of the error." Parker v. Defense Logistics Agency (1980).

${ }^{6}$ An employee may use negotiated grievance procedures only if two conditions are met. First, he/she must be a member of a bargaining unit. This is not the same as being a union member. It means that a union has won the right to represent employees at that location, and must represent all bargaining unit employees, whether or not they are paid union members. Second, the type of action taken must be covered by the negotiated contract. Civil service reform permits but does not require, a broad scope of coverage for negotiated grievance procedures.

The Veterans Preference Act of 1944 actually extended these rights not only to veterans but to others eligible for veterans preference, i.e., spouses and dependents of deceased or disabled veterans.

${ }^{8}$ In FY 1980, MSPB Field Offices processed 93 percent of the cases brought under Civil Service Reform within the 120-day limit. There was a sizable backlog of cases which originated before civil service reform. MSPB did less well with these cases, meeting the four-month deadline only 61 percent of the time. See MSPB (1981).

${ }^{2}$ See U. S. Office of Personnel Management, SES Special Study of Managerial Flexibility during a Change in Administration (forthcoming). It should be pointed out that subtle political pressure will not show up in any type of record keeping system since involuntary reassignments are evidenced only if someone complains about the reassignment.

'The number of resignations in lieu of adverse action increased slightly, from 1,030 in 1978 to 1,242 in 1980. Figures taken from U. S. Office of Personnel Management's Central Personnel Data File. Comparable figures for 1981 will not be available until mid-1982.

\section{REFERENCES}

Campbeil, A. K. (1977). "Breaking the Bureaucratic Bond." Remarks before the Third Annual Institute for Kansas Legislators, Kañsas State University, Manhattan, Kansas (December).

Campbell, A. K. (1978). "The Battle Over Bureaucracy." Time magazine (March).

Douglas v. VA (1981). Merit Systems Protection Board, Docket Number AT075299006.

General Accounting Office (1978). A Management Concern: How to Deal with the Nonproductive Federal Employee. FPCD-78-71. (August). 
McAuliffe v. New Bedford (1892). 155 Mass. 216, 220.

Merit Systems Protection Board (1981). Study of MSPB Appeals Decisions for FY 1980. Office of Merit Systems Review and Studies (May).

Merritt v. Justice (1981). Merit Systems Protection Board, Docket Number PH075209058.

Parker v. Defense Logistics Agency (1980). Merit Systems Protection Board, Docket Number PH053149001.

Reorganization Plan No. 2 (1978). Law 95-454 (October 13).

Rosenbloom, D. H. (1977). Federal Service and the Constitution. Ithaca, N. Y. : Cornell University Press.

U. S. Office of Personnel Management (1980). Federal Employee Attitudes: Phase 1, Baseline Survey (Narch).

(forthcoming). Federal Employee Atitudes: Phase 2: Follow-up Survey.

(forthcoming). SES Special Study of Managerial Flexibility during a Change in Administration.

U. S. President's Personnel Management Project (1977). Vol. 1, Final Staft Report. Washington: Government Printing Office (December). 